\title{
Modelos de ecología de la comunicación: análisis del ecosistema comunicativo
}

\author{
Andrés Felipe Giraldo-Dávila ${ }^{1}$ \\ Claudia María Maya-Franco²
}

Recibido: 2015-09-02

Enviado a pares: 2015-09-09
Aprobado por pares: 2015-10-27

Aceptado: 2015-10-30

DOI: 10.5294/pacla.2016.19.3.4

Para citar este artículo / To reference this article / Para citar este artigo Giraldo-Dávila, A. F. y Maya-Franco, C. M. (2016). Modelos de ecología de la comunicación: análisis del ecosistema comunicativo. Palabra Clave, 19(3), 746-768. D0I: 10.5294/ pacla.2016.19.3.4

\section{Resumen}

El objetivo del artículo es describir tres modelos de comunicación digital que permitan visualizar, y poner en relación, aspectos del concepto de ecología de la comunicación y analizarlos desde una perspectiva crítica. Lo anterior con el propósito de dar cuenta de fenómenos comunicacionales contemporáneos, como el papel del ser humano en los procesos de comunicación, los efectos de los nuevos medios en las dimensiones psicológicas y de comportamiento y las repercusiones políticas en cuanto a las dinámicas de poder y persuasión. La creación de una nueva ecología cultural, la metáfora del efecto invernadero por la saturación ante los amplios flujos de información y el papel de los procesos de comunicación en la sociedad-red constituyeron las tres vertientes esquematizadas que tuvieron como presupuesto los aportes de las ciencias humanas, la filosofía y los estudios de la comunicación a la hora de elaborar teóricamente el concepto de ecología de la comunicación.

\section{Palabras clave}

Ecología de la comunicación; modelos de comunicación digital; teoría de la comunicación (Fuente: Tesauro de la Unesco).

1 Universidad de Medellín. afgiraldo@udem.edu.co

2 Universidad de Medellín.cmaya@udem.edu.co 


\section{Models of Communicative Ecology: An Analysis of the Communication Ecosystem}

\section{Abstract}

The objective of this article is to describe three digital communication models that make it possible to visualize and relate aspects of the concept of "communicative ecology" and to analyze them from a critical perspective. The purpose is to account for or explain contemporary phenomena in communication, such as the role of the human being in communication processes, the effects of new media on psychological and behavioral dimensions, and political repercussions in terms of the dynamics of power and persuasion. The creation of a new cultural ecology, the metaphor of the greenhouse effect through saturation from the huge flows of information, and the role of communication processes in the network society were the three schematized aspects that took the contributions of the human sciences, philosophy and communication studies as a proposal when it came to developing the concept of "communicative ecology" from a theoretical standpoint.

\section{Keywords}

Communicative ecology; digital communication models; communication theory (Source: Unesco Thesaurus). 


\section{Modelos de ecologia da comunicação: análise do ecossistema comunicativo}

\section{Resumo}

O objetivo deste artigo é descrever três modelos de comunicação digital que permitirão visualizar e relacionar aspectos do conceito de ecologia da comunicação, além de analisá-los sob uma perspectiva crítica. Isso com o propósito de dar conta de fenômenos comunicacionais contemporâneos, tais como o papel do ser humano nos processos de comunicação, os efeitos dos novos meios nas dimensões psicológicas e comportamentais, e as repercussões políticas quanto às dinâmicas de poder e persuasão. A criação de uma nova ecologia cultural, a metáfora do efeito estufa pela saturação ante os amplos fluxos de informação e o papel dos processos de comunicação na sociedade-rede constituíram as três vertentes esquematizadas que tiveram como pressuposto as contribuições das ciências humanas, da filosofia e dos estudos da comunicação na hora de elaborar teoricamente o conceito de ecologia da comunicação.

\section{Palavras-chave}

Ecologia da comunicação; modelos de comunicação digital; teoria da comunicação (Fonte: Tesauro da Unesco). 


\section{Introducción}

La identificación de tres modelos que abordan de manera directa aspectos teóricos de la ecología de la comunicación constituye el principal insumo para llevar a cabo un análisis acerca del papel central que tiene el hombre en los procesos de comunicación, sus efectos en las dimensiones psicológicas y de comportamiento y las repercusiones políticas en cuanto a las dinámicas de poder y persuasión. Los esquemas de comunicación seleccionados son en su orden: 1) modelo de comunicación digital para ambientes glocales, 2) modelo efecto invernadero y ciclo de vida de los medios y 3) los medios y la comunicación en la sociedad-red. Estos modelos permiten hacer reinterpretaciones y trazar líneas de pensamiento acerca de la ecología de la comunicación, teniendo como eje central la relación entre el avance técnico, la individualización de las audiencias y la creciente sensación de un amplio ecosistema de la comunicación que se da desde el punto de vista de la democratización del acceso a la información.

Los tres modelos diseñan nuevas configuraciones del ecosistema de la comunicación en la actual era de la información tecnológica y la digitalización de los procesos humanos. La virtualidad es una escenografía convergente para los medios bajo nuevas estructuras de generación de contenidos, mediaciones sociales y formación de audiencias. La ecología de la comunicación, más allá de la perspectiva instrumentalista que los medios ofrecen sobre la realidad, es una perspectiva de posicionamiento en torno a los efectos de la sociedad mediada y las transfiguraciones de lo digital-tecnológico en las variables humanas y la realidad.

\section{Marco teórico}

La ecología de la comunicación permite pensar los fenómenos comunicativos más allá de la comprensión meramente instrumentalista y asumirla como un ecosistema en el que se producen traslapes permanentes entre naturaleza y cultura, a partir de la hipótesis de que internet es el medio en el que el famoso planteamiento de McLuhan: el medio es el mensaje, se pone de manifiesto. Este enunciado, por otra parte, es precursor de este modo integrador de pensar el fenómeno de la comunicación en la actualidad. 
El más famoso de los epigramas de McLuhan: el medio es el mensaje, en declaración de la inseparabilidad del mensaje y el medio, sugiere la unidad completamente ecológica que hay en la interacción entre lo físico de los medios y lo metafísico de la cultura (Stephens, 2014, p. 2).

El concepto de ecología de la comunicación se aleja de la comprensión antropocentrista, cuyo modelo erige a los seres humanos como origen y meta última. El modelo clásico de la comunicación que centraba su análisis en la dinámica emisor-canal-mensaje-receptor es sustituido por una perspectiva que asume la determinación recíproca entre el entorno de la comunicación y aquellos que se comunican, dando paso a la reflexión acerca de las posibilidades y los riesgos actuales del entorno (ecosistema) comunicativo. Lo anterior porque el modelo tradicional de la comunicación, que pone a los seres humanos como el comienzo y la meta, no da cuenta del fenómeno comunicativo en una era de máquinas inteligentes y de comunicación mediada por computadores o inteligencia artificial.

Desde un punto de vista general, el concepto de 'ecología de la comunicación' abarca casi todos los aspectos de los procesos comunicativos, desde las relaciones entre los medios y la economía, hasta las transformaciones perceptivas y cognitivas que sufren los sujetos a partir de su exposición a las tecnologías de la comunicación (Scolari, 2015, pp. 17-18).

La ecología de los medios, como propuesta teórica que pretende describir objetivamente el ambiente o entorno comunicativo de la actualidad, se enmarca en el efecto que estos tienen en los sujetos que los usan. Ecología implica un ambiente que combina estructura, contenido e impacto sobre los usuarios (Postman, 1970, citado en Scolari, 2015, p. 29). Esta dimensión ambiental de la ecología comunicativa se centra en el modo en que los medios construyen la realidad.

Esta modalidad conceptual constituye un enfoque integrador de los procesos comunicativos y del modo en que los medios se interrelacionan. Nystrom (1970), citado en Scolari (2015, p. 30), indica que ningún medio actúa de forma aislada y que, al contrario, unos tienen efecto sobre otros, lo 
cual constituye una dimensión intermedial o ecológica. Tanto la comunicación como la ecología establecen un vaso conductual en la medida en que se establecen vínculos entre la técnica y sus efectos en el ser humano. El impacto de las técnicas de la comunicación se imbrica con la naturaleza humana. Nevitt (1982), citado en Romano (2004), sostiene que la ecología de la comunicación se debe centrar en los efectos sociales de las extensiones tecnológicas incluso más que en los efectos eminentemente técnicos.

La importancia de visualizar un sistema ecológico de los medios nace de la excesiva saturación informativa que se reproduce en cadena a través de estos, ocasionando un efecto invernadero. ${ }^{3}$ Esta metáfora pretende dar cuenta del sobrecalentamiento, producto de la cantidad de información que recrea uno o varios esquemas de la realidad. La migración de los canales convencionales de difusión a la convergencia mediática digital ha modificado las formas de producir, distribuir y consumir el conocimiento. Según Scolari:

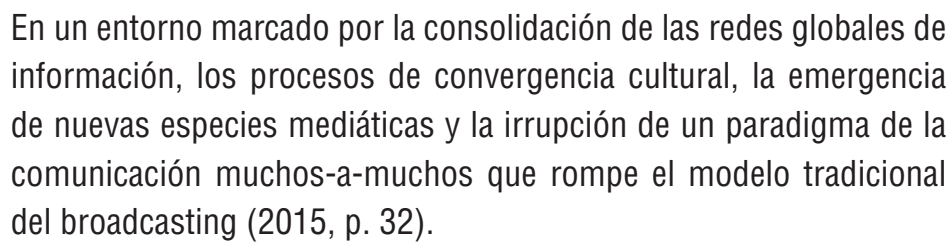

La ecología de la comunicación toma la bandera de la reinterpretación de las realidades expuestas por los medios, su grado de influencia en los sujetos, las modificaciones en la creación de contenidos, producto de las convergencias transmedias y la formación de audiencias y sus nuevos hábitos de consumo hacia la individualización. El desarrollo de una nueva generación de medios interactivos, apoyados por la plataforma World Wide Web, han modificado las reglas convencionales de los medios tradicionales hacia una transmedia, lo cual hace que se hable de nuevos ecosistemas mediáticos integrados.

3 Término eminentemente usado en el argot medioambiental para determinar el sobrecalentamiento de la Tierra producto de los procesos industriales y las dinámicas sociales. 
La Ecología de la comunicación es la ciencia de las relaciones e interacciones que existen entre las diferentes especies de actividades de comunicación dentro de un sistema social disperso en un territorio. Es una ciencia estadística de los medios de comunicación, de los mensajes que transportan, de las relaciones entre ellos y con los públicos y la sociedad... la Ecología de la comunicación parte de la idea de que es posible realizar una descripción de la actividad humana en términos de comunicación, en función de la naturaleza de los mensajes enviados en una repartición estadística de estos (Costa, 2011, p. 20).

La comunicación es un proceso inherente al hombre en la necesidad de mantener contacto con los demás en un entorno social. De ahí la necesidad de vincular la naturaleza humana con los usos técnicos de los medios y el grado de adaptación de las personas a esos medios. La oleada de las tecnologías de la información y de la comunicación han potenciado un concepto económico-político donde la comunicación es un instrumento de poder persuasivo de sujetos a sujetos. Sin embargo, la ecología de la comunicación actúa en un nivel crítico en torno a la economía política de la información y trata de posicionar una perspectiva donde el entorno comunicacional debe adaptarse a las condiciones humanas, y no al contrario. Esta premisa, no obstante, queda en entredicho cuando se esquematizan realidades que ponen de manifiesto el hecho de que son los medios, muchas veces, los que trazan las líneas de juego de los sujetos sociales. El grado de emancipación, saturación o fervor por el consumo de accesorios informativos tecnológicos limita la capacidad crítica que el ser humano debe asumir frente a las tendencias tecnocentristas que dibujan relaciones de poder y dominio a través de las cuales conglomerados económicos orientados por lógicas de consumo subsumen al hombre en la condición de cliente sometido por estructuras superiores de la tecnología y conectividad en red.

En este orden de ideas, el concepto de ecología de la comunicación, también conocida como Escuela de Toronto, Escuela de Nueva York, Escuela de San Luis o Mediología, pretende dar cuenta, metafóricamente, del fenómeno de la comunicación en la época actual, al tiempo que constituye un campo privilegiado y promisorio para la investigación en el ámbito de las ciencias humanas. Esto por varios motivos: 
En primer lugar, no concibe la comunicación como un instrumento entre otros, que quienes se comunican utilizan y luego desechan. Se aleja también de la idea según la cual la relación comunicación-naturaleza sería dicotómica y la piensa más bien como una relación continua, sin afuera, omniabarcante, a saber, como un environment. El entorno de la comunicación no es una segunda naturaleza sino la naturaleza. A su vez, lo anterior implica superar el dualismo que presupone el famoso modelo de comunicación en el que hay un emisor, un destinatario y un discurso. Esta concepción supone una función meramente instrumental al lenguaje, así como un carácter aislado respecto de las conciencias que a través de él establecen un nexo de comunicación.

Estas críticas del carácter meramente instrumental, así como a las apologías del diálogo, ponen de manifiesto que para pensar la especificidad de la comunicación parece pertinente pensar el fenómeno de la "cultura técnica”, en lugar de encarnar la fidelidad al descrédito ancestral. Es decir que debe plantearse la pregunta por el modo en que, en la era de su vertiginoso ascenso tecnológico, estos median — toda vez que tienen siempre una intención, no son inocentes e intervienen, al tiempo que son intervenidosla vida humana y sus formas de organización. Preguntarse, pues, por su relación con las estructuras sociales, cognoscitivas, ideológicas, culturales, políticas y públicas, a partir de estrategias definidas institucional y políticamente. El análisis podría también orientarse a la objetivación de los lugares de procedencia de los constreñimientos y limitaciones que atraviesan la relación comunicación-sociedad y su relevancia política y pública. Estas preguntas se hacen cada vez más pertinentes en el ámbito de las ciencias humanas.

La invitación a pensar el fenómeno de la comunicación a partir de la exigencia de su nueva configuración está del lado de la propuesta que hace Vattimo de elaborar para el presente, para los fenómenos contemporáneos, una "ontología hermenéutica contemporánea" (Vattimo, 2004, p. 25); es decir, una perspectiva de análisis que se ocupe de los fenómenos actuales en un contexto histórico y que entre en diálogo con las ciencias humanas y de la información, con la crítica estética y las tecnologías y, en general, con 
todas las voces que en el presente, también en virtud de los avances tecnológicos, han tomado la palabra.

De este modo devuelve el pensamiento sobre la cultura la función que la sociedad demanda de la filosofía: la de colaborar en la comprensión de lo que ocurre; la de facilitar la interpretación de lo que ya se da y puede darse, de la praxis y experiencias que se tienen de los fenómenos políticos, históricos, y hasta cotidianos (Vattimo, 2004, p. 27).

Las tecnologías emergentes o nuevas tecnologías dan lugar a una proliferación de voces, en virtud de la cual también se crítica la ausencia de una objetividad. Sin embargo, el anhelo ilustrado de objetividad va cediendo terreno a la plurivocidad que permite la superabundancia de canales, páginas web, imágenes y sonidos de todo tipo. Esta condición resulta positiva toda vez que le ha dado la palabra a minorías, así como a manifestaciones que, aun cuando siguen siendo marginales, requieren cuando menos de un análisis, al que Vattimo considera más urgente que el de la exigencia de objetividad. Dicha objetividad, por otra parte, resulta contradictoria. Si bien es cierto que pensar el vínculo entre medios, poder, política e intereses económicos es imperativo en la actualidad, también es cierto que dicho imperativo debe distanciarse del ánimo de univocidad en el contexto de la plurivocidad.

Así como una sociedad de la comunicación generalizada, Vattimo considera que la actual es una sociedad de las ciencias humanas y que ambos aspectos de lo social favorecen la construcción, desde planos diferentes, de imágenes del mundo que constituyen su "objetividad”. Esta producción de imágenes, criticable desde la perspectiva platónica del original y la copia, la verdad y la apariencia, puede ser vista como una manifestación de la libertad en el reconocimiento de que la imagen no es necesariamente simulacro, en el sentido de copia engañosa, sino que: "El sistema mediaciencias humanas funciona, cuando mejor funciona, como emancipación, sólo por cuanto nos coloca en un mundo menos unitario, menos cierto, y, por tanto, también bastante menos tranquilizador que el del mito" (Vattimo, 2004, p. 110). 
Así, el concepto de ecología de la comunicación permite una toma de distancia respecto de la perspectiva empiricista así como de su opuesto: la autoconciencia del racionalismo, y dirige el interés hacia la urdimbre complicada de discursos e imágenes (del mundo) que surgen de la interrelación entre la sociedad y los medios de comunicación. Esta urdimbre, que cada vez adquiere mayor densidad, pone de manifiesto una condición que, no por parecer un lugar común, deja de ser un motivo digno de reflexión, a saber: que la relación entre innovación tecnológica y comunicación efectiva parece ser inversamente proporcional, así como es directa la proporción entre la capacidad teórico reflexiva que han alcanzado las ciencias humanas, el crecimiento de la información que la sociedad actual posee sobre sí misma y la persistente opacidad de los problemas sociales vinculados a la comunicación. En el mismo orden de ideas, la gran complejidad que reviste la mediación comunicación-sociedad comporta aspectos insospechados y alcances que, en la inmanencia del fenómeno, no resulta fácil objetivar.

En segundo lugar, y esta es una característica novedosa y determinante, asume el reto que supone la expectativa de que, justo en una cultura mediada, como la actual, residan posibilidades de transformación social, y esto en las dos fases del concepto: la ecologista-ética (Claus Eurich, Mettler Von Meibom y Vicente Romano) que piensa la naturaleza como interacción del hombre con su entorno, ya sea este natural o cultural, y propone el carácter ecológico como una suerte de imperativo categórico que regule riesgos de la comunicación, tales como la manipulación de la opinión pública con fines económicos y políticos. ${ }^{4}$

La Ecología de la comunicación implica trabajo colectivo, conectividad, confianza recíproca e igualitaria. No permite la violencia lingüística, subordina los intereses privados a los comunes o colectivos, implica también una comunicación dialógica y una actitud que tiene que ver con los conceptos de totalidad, interdependencia, relación, destino común, bien común, actitud holística, abierta, no excluyente (Romano, 2004, p. 257).

4 Vale decir que esta preocupación ya motivaba la formulación, por parte de Adorno y Horkheimer, del concepto de 'industria cultural' (1945) y que tiene que ver con la homogeneización de los seres humanos mediante una proscripción de la heteronomía, en últimas, sobre la posibilidad de un abuso de poder por parte de grupos hegemónicos. 
Esta fase también piensa en el papel que los medios cumplen en la destrucción del medio ambiente, así como en el hecho de que construyen una seudorrealidad superpuesta a la empírica, un segundo medio ambiente. La segunda fase (Vicente Morano) se deriva de la anterior y, centrándose menos en los aspectos tecnológicos, estudia las condiciones ideales, de polución mínima, para la comunicación, respecto del poder, el control, la participación política, los impactos sociales, económicos, subjetivos y del orden de la interacción. Ambas vertientes se ocupan tanto del aspecto tecnológico de los dispositivos, como del aspecto cultural de la comunicación. Se trata de superar un tipo de análisis que piensa a las tecnologías por un lado y a los usuarios por otro y privilegie, a tenor de la metáfora, el carácter simbiótico de la relación naturaleza-cultura, a fin de estudiar las relaciones que los medios permiten entre los individuos y los grupos humanos con la cultura y el medio ambiente, es decir, con su entorno. La relación entre el hombre y la naturaleza de la que hace parte es análoga a la relación entre el hombre y la comunicación. Es decir que el entorno comunicativo constituye, en efecto, el entorno natural del hombre.

La metáfora de la aldea global, formulada por Marshall McLuhan ${ }^{5}$ en la década de 1960 a propósito de la radio, el cine y la televisión, es precursora, en una época previa a la de internet, de la de ecología de la comunicación. En efecto, aquella nombra, a propósito de la radio, el cine y la televisión, el carácter envolvente, de simultaneidad, inmediatez, cruce de tiempos y espacios, que terminan por componer, con elementos distantes espacio-temporalmente, el aquí y el ahora de los seres humanos.

De la metáfora hace parte el hecho de que el de la comunicación sea un entorno sin afuera en que los traslapes, metafóricos en el sentido material del concepto, entre naturaleza y cultura, de los que da cuenta la existencia de máquinas inteligentes, inteligencia artificial, virus informáticos, ambientes virtuales, impresión 3D de prótesis, ingeniería genética, entre otros, hacen que la frontera entre comunicación y cultura sea cada vez más tenue:

5 A este sociólogo llega a considerársele, incluso, un profeta de internet: "Sobre la estrecha relación entre las tesis de McLuhan y el desarrollo de internet —el medio inteligente_, Piscitelli (2005) afirma que 'el medio favorito de McLuhan hubiese sido el internet”' (Islas, 2009, p. 26). Lo anterior porque decir que el medio es el mensaje implica afirmar que el entorno de la comunicación define a su vez a quienes se comunican. 
Cuando el genoma es "mapeado" y la información genética es traducida al código digital, el territorio se convierte en el mapa. La generación de la "vida sintética" implica el proceso inverso. Cuando el código es transpuesto en información genética, el mapa se convierte en el territorio (Stephens, 2014, p. 13).

Por último, el concepto nombra un hecho ya anticipado por Neil Postman (1998): “Un nuevo medio no agrega algo; lo cambia todo”. El libro electrónico no anula el libro impreso, la prensa digital no implica la obsolescencia de los periódicos, la adición no ocurre por sustitución sino por complementación o modificación, en los que no solo los humanos interactúan a través de los medios, sino que interactúan con medios que a su vez interactúan entre sí.

El problema es el hábito de entender la interacción de los diferentes elementos tecnológicos y semánticos por analogía con, en lugar de entenderla por su conexión material con ecosistemas que son más que humanos. La alternativa sugerida es atender a lo material y a lo encarnado, pensando lo semántico a la vez como material e inmaterial, y apreciando que las metáforas, en sí mismas, son recursos, tanto materiales como inmateriales (Stephens, 2014, p. 6).

\section{Modelos de comunicación: interpretaciones conceptuales de la ecología de la comunicación}

A continuación, se analizarán tres modelos de comunicación, los cuales abordan de manera directa aspectos conceptuales de la ecología de la comunicación. Los modelos son una representación de la realidad social, no pretenden una verdad absoluta en sí misma, sino una aproximación que posibilite el análisis esquemático de los entornos humanos, dentro de ellos el papel de la comunicación como proceso social dentro de un proceso macro de la estructura sociopolítica. En primer término, se analizará un modelo propuesto por Octavio Islas que se denominó modelo de comunicación digital para ambientes glocales (figura 1); en segundo lugar, se analizó el modelo diseñado por Ross Dawson denominado modelo efecto invernadero y ciclo de vida de los medios (figura 2), y el tercero se llamó los medios y la comunicación en la sociedad-red (figura 3), diseñado también por Dawson. 


\section{Figura 1. Modelo de comunicación digital}

para ambientes glocales

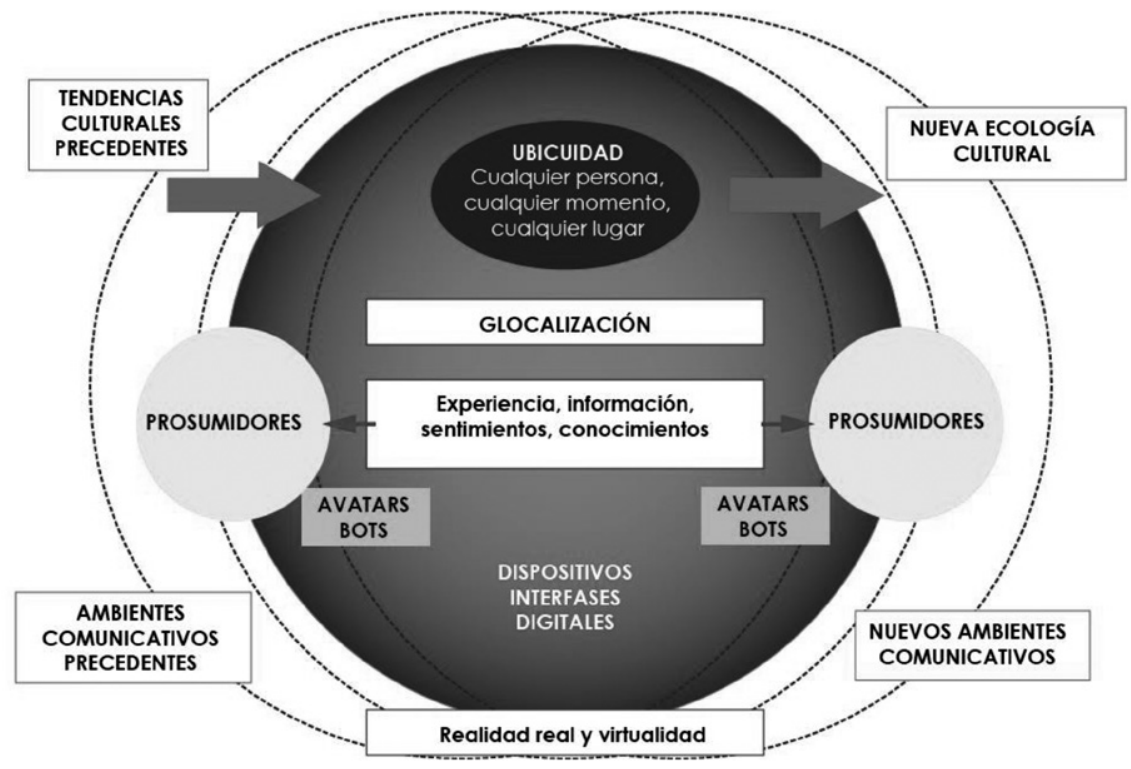

Fuente: Islas (2015).

Figura 2. Modelo efecto invernadero y ciclo de vida de los medios

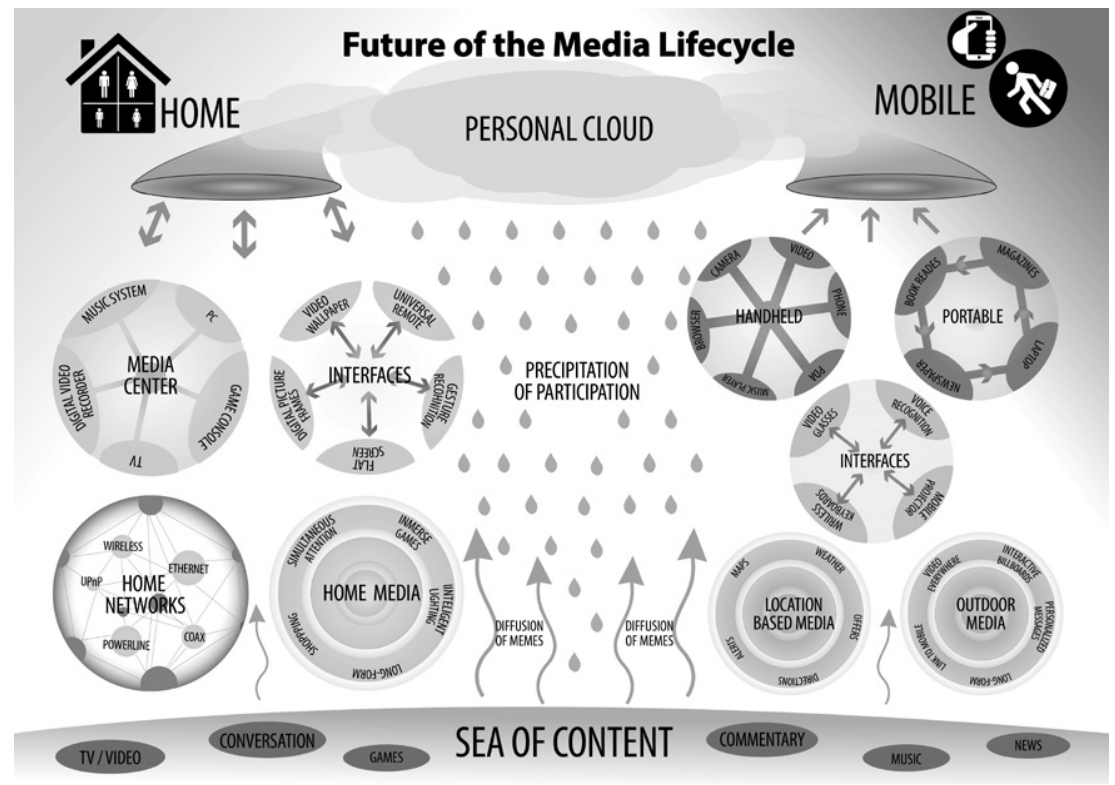

Fuente: Dawson (2008). 


\section{Figura 3. Los medios y la comunicación en la sociedad-red}

Trend Blend 2007+

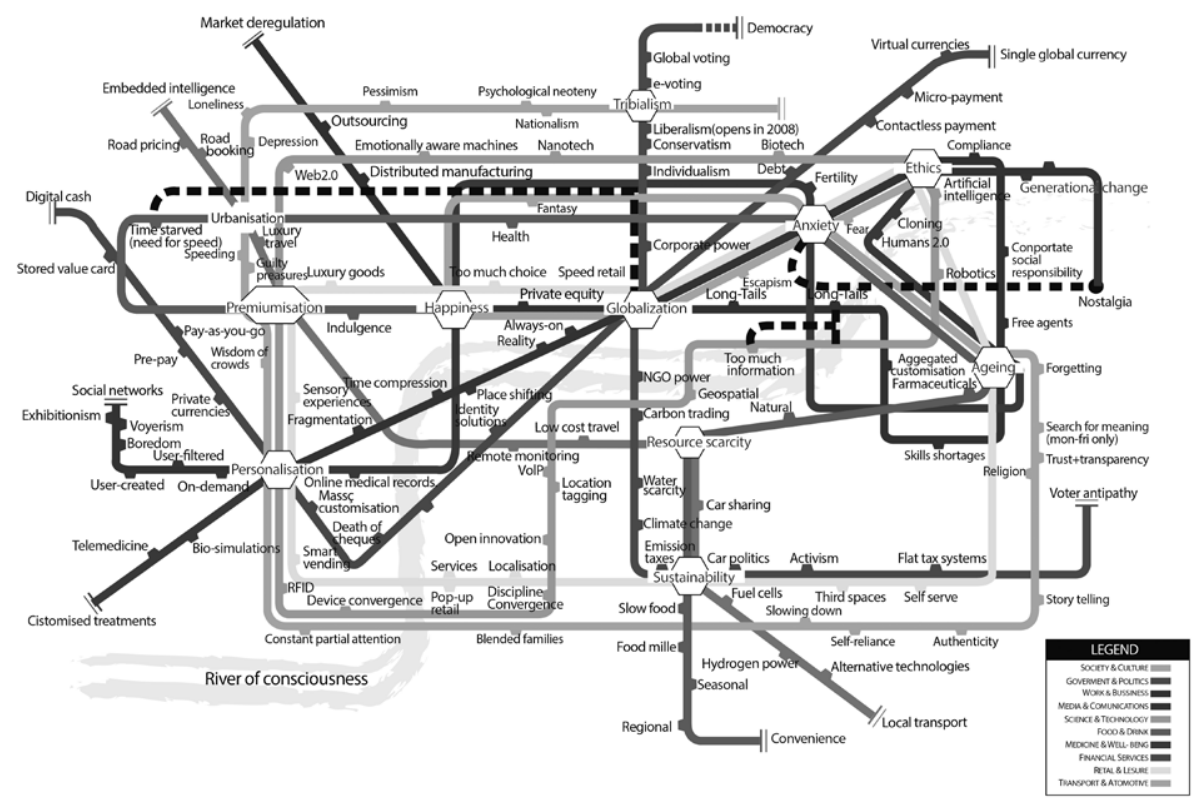

Fuente: Dawson (2006).

Islas (2009) sostiene en este modelo que se está ante una ecología de la cultura, propiciada por el consumo de los medios en cualquier espacio geográfico, por lo que la glocalización es determinada por el consumo en un espacio real específico y la interpretación de la realidad obedece a lo que los medios influyen en las mentes y en los comportamientos de los sujetos.

En un ambiente de ecologías culturales precedentes, se pone en marcha la nueva ecología cultural marcada por el fenómeno de la globalización en la cual los dispositivos digitales posibilitan nuevas formas de interactuar más allá de la simple recepción de información, para permitir el desarrollo del rol de prosumidor y de las posibilidades de la ubicuidad en la cual la web pone a una persona, en cualquier momento y en cualquier lugar a interactuar a través de la misma (Islas, 2015).

La ecología de la comunicación se ve reflejada en este modelo en la medida que el sujeto está en un ecosistema cultural produciendo y con- 
sumiendo contenidos informativos de manera simultánea, originando así nuevos ambientes y entornos culturales, donde el concepto de 'ubicuidad' es similar al de ecosistema. El sujeto crea y pone a disposición una amplia gama de información a través de dispositivos o interfaces digitales móviles o estacionarias que se comparten con otros sujetos, tras lo cual se generan nuevos actores y entornos comunicativos que permiten construir nuevos ambientes culturales, como consecuencia de la exposición a medios convergentes digitales. Los elementos de la realidad se transportan en canales informacionales digitales creados por los mismos prosumidores, hasta tal punto que se decantan nuevas realidades. "Al explorar las capacidades de los dispositivos e interfaces digitales, los prosumidores gestarán las condiciones necesarias para acceder a ambientes comunicativos más complejos, transitando a una ecología cultural” (Islas, 2015).

El cambio más significativo que experimenta el nuevo ambiente de los procesos comunicacionales lo constituye el papel que desempeña el consumidor, el cual muta hacia prosumidor, concepto utilizado para determinar que, hoy por hoy, no hay una dependencia obligada de la existencia de una corporación generadora de contenido informativo para generar audiencia, sino que son los mismos consumidores de medios los que pueden constituirse en fuente generadora de información a través del uso de plataformas digitales con conexión en tiempo real. El prosumidor para este modelo es el que está creando una sociedad de la ubicuidad producto del empoderamiento de las herramientas de acceso a la información, avanzando así hacia un ecosistema cultural de trabajo colaborativo, reduciendo el grado de dependencia de la era de los medios masivos de comunicación. Con la conexión en tiempo real, los paquetes de datos móviles, las redes sociales, los motores de búsqueda y las enciclopedias colaborativas, los medios masivos de información han mutado hacia estas plataformas para generar contenidos donde las audiencias producen interacciones y crean contenidos paralelos a los de las empresas informativas: videos, audios, caricaturas, foros, blogs e imágenes, que en muchas ocasiones sirven de fuentes primarias para los mismos medios informativos o se constituyen en tendencias por el elevado tráfico de usuarios que acceden a la información. 
El aporte de este modelo al concepto de ecología de la comunicación está en la metáfora sobre el efecto invernadero que produce el calentamiento global, donde la penetración de los rayos del sol que ingresan en la atmósfera terrestre para generar un adecuado "clima" no alcanzan a ser evacuados y genera una saturación de los rayos ultravioleta que originan un efecto invernadero que afecta el clima y los ecosistemas.

Asimismo pasa con la sociedad de la información en la medida en que esta es un mar originado y constantemente alimentado por el crecimiento progresivo de las autopistas de la información, que hacen del hombre un sujeto rodeado de enciclopedias, datos, noticias, publicidad, videos, chats, imágenes, reproducidos a través de los accesorios que consume tanto en el hogar como en su teléfono móvil. La excesiva exposición de las personas a la información genera una saturación tal que el sujeto de la comunicación se sobrecalienta hasta tal punto de que no alcanza a absorber la información disponible, ubicando al consumidor de información como un sujeto manipulable, persuadido y expuesto a una realidad social mediada en contraposición a un sujeto con la capacidad de crear una sociedad de conocimiento científica a partir del buen uso de la información.

El ecosistema que se expone en este modelo lo origina la sociedad de consumo. Por un lado, el ser humano como sujeto de la comunicación está conectado en tiempo real a través de la amplia oferta de equipos en red tanto en los hogares como en el teléfono móvil. Sánchez, Botero y Giraldo (2011) analizan este modelo de comunicación digital a partir de la exposición de las personas a un mar de contenido de información para su uso personal, el trabajo, los hábitos de consumo y entretenimiento, lo que les permite a los sujetos apropiarse de la información de manera individual, lo cual genera una nube personal de hábitos y actitudes en torno a las diversas formas de comunicación mediada. El ecosistema de la comunicación está saturado, generando así un efecto invernadero por la sobrecarga de información que afecta y transforma los estereotipos sociales e influye en la toma de decisiones de las personas.

Este silogismo que sincroniza la saturación de información con la figura del calentamiento global crea un imaginario de la realidad en el senti- 
do que, si bien nunca antes el ser humano había estado tan informado y con la posibilidad de empoderarse de los contenidos para su propio progreso personal y social, esta situación lo que origina es un sujeto más vulnerable frente a las estructuras de poder que indican las tendencias a las que están sometidos los consumidores de información, desde lo político, lo económico, lo social y lo cultural.

El consumo de comunicación se evidencia en la saturación de accesorios que producen los mismos contenidos como una estrategia para crear una dependencia hacia el sujeto para que esté conectado en todo momento. Las personas deben estar conectadas en tiempo real y en distintos escenarios, que van desde lo personal, lo familiar, lo laboral y lo social. El modelo hace énfasis en el excesivo consumo de medios, tanto móviles como en hogares, los cuales moldean la vida de las personas. Los contenidos se ajustan a las plataformas multimodales como estrategia de consumo, generando así una alta dependencia de las personas hacia el hecho de sentirse seguras en la medida en que tienen acceso a la información. No obstante, la amplia gama de plataformas y el avance de dispositivos saturan el ecosistema informativo hasta tal punto que las personas se sobrecalientan de información, y esto las hace más expuestas y vulnerables a estructuras económicas de poder.

Este modelo de la comunicación en sociedad-red busca ubicar la variable comunicativa como parte de un entramado que conecta otras dimensiones de la vida social que tiene como epicentro la globalización. Este ecosistema simula una metáfora de mapa del sistema de transporte masivo de una gran ciudad con todas las estaciones, epicentros masivos de gran flujo, puntos de encuentro y llegadas en las áreas periféricas.

El lugar concéntrico o gran estación dentro del ecosistema lo constituye la globalización como variable de intensificación de todo el conjunto de interacciones sociales, políticas, económicas y culturales que modifica los conceptos de 'relacionamiento', 'espacio' y 'tiempo'. Este modelo tiene como sustento la estructura de la globalización para explicar el entramado complejo de la sociedad, similar a las estructuras complejas 
de una ciudad moderna que requiere posibilidades de movilización ágiles y efectivas.

La sociedad actual propone y requiere una serie de segmentos o líneas de flujo de interacción en red. Son diferentes las fuerzas, movimientos, tendencias y aspectos que se entrecruzan para construir el universo de posibilidades que las personas, las comunidades, las organizaciones y las sociedades tienen con la mejoría de los procesos tecnológicos que han propiciado un avance en la comunicación y la información (Sánchez, Botero y Giraldo, 2011, p. 100).

La ansiedad y la felicidad constituyen dos puntos de encuentro cercano al epicentro, dado que son variables ligadas a las necesidades creadas para que el hombre alcance la prosperidad que la globalización le exige. Otras estaciones importantes del mapa los constituyen la ética, analizada desde los cambios tecnológicos y la manipulación de la vida desde la genética, la biotecnología y la inteligencia artificial; la sostenibilidad ambiental, como consecuencia de la escasez de recursos, la industrialización y las variaciones del clima; el tribalismo como constructo de una sociedad que debe conservar más los valores culturales en detrimento de un nacionalismo fallido; el urbanismo como fenómeno global derivado de la vida en las ciudades como estándar de prosperidad, lo cual le da paso al personalismo como punto de referencia en el valor individual por delante de las premisas colectivas, y el grado de especialización donde el valor agregado marca el punto de diferencia en las ventajas competitivas tanto de personas como de sociedades geográficamente referenciadas.

Los procesos inherentes a la comunicación están circunscritos a lo largo de varias rutas de la red de estaciones, las cuales están descritas en la línea verde del mapa, atravesando todas las grandes estaciones y circundando la matriz principal de globalización. La cantidad de información, la web geoespacial, los VoIP, el monitoreo electrónico, la innovación, la convergencia, la identificación por radiofrecuencia (RFDI 'Radio Frequency IDentification'), la web, las máquinas con conciencia emocional, la nanotecnología, la biotecnología, la inteligencia artificial y la robótica hacen parte 
de una ruta que circunda por todo el ecosistema y que de una $u$ otra forma son evidencias del uso de las tecnologías de la información y de la comunicación que como instrumento están transformando la esencia humana. También se destaca en el ecosistema la ruta trazada por la línea azul oscura de donde inicia con la estación redes sociales que describe a un usuario-creador, entendido como prosumidor. Elementos como el exhibicionismo, el voyerismo, el hastío, el filtro de usuarios, la fragmentación, la realidad, el cambio generacional y la nostalgia trazan una línea discontinua hacia la ansiedad.

Este modelo de sociedad-red identifica tendencias en ámbitos diversos de la vida social, los cuales se califican como promisorios y decepcionantes; apocalípticos o integrados, que, en palabras de Eco (1993), indican que, mientras una visión apocalíptica describe la decadencia, los integrados prefieren actuar, producir o emitir los mensajes; constituye la prédica de dos adjetivos complementarios adaptables. Promisorio o catastrófico, el enviroment social hoy está determinado por los procesos emancipatorios de la globalidad que está modificando la esencia misma del ser humano desde su genética hasta su ética. La comunicación funge como plataforma instrumental y testigo social de las transformaciones.

\section{Conclusiones}

El concepto de ecología de la comunicación constituye una apuesta potente y pertinente para pensar los fenómenos de la comunicación en la era digital. Lo anterior en virtud de su distancia de modelos antropocéntricos que no dan cuenta de las dinámicas comunicativas actuales, así como de su carácter interdisciplinar, consecuente con la plurivocidad actual de discursos que abren a derivas interpretativas y comprensivas más afines a los fenómenos de los que se ocupan. La ecología de la comunicación constituye un enfoque que integra, bajo la metáfora del medio ambiente, todos los procesos comunicativos, así como la interrelación entre ellos y el modo en que, a partir de todo este conjunto de interacciones, se construye, entre los seres humanos que se comunican, pero también entre los dispositivos a través de los cuales se comunican, la imagen de lo real. La ecología de la comunicación piensa dos derivas posibles de los fenómenos comunicativos en tiempos de globalización; por una parte, las posibilidades de participa- 
ción, o bien, la democratización de la participación y la interacción. Pero, también, en su polo opuesto, los riesgos de alienación simbólica y manipulación ideológica que pueden tener lugar en el interior de dicho sistema.

Los medios de comunicación, como estimulaciones sensoriales de los seres humanos, compiten entre sí por lograr la mayor legitimidad en el posicionamiento preferencial de las personas (Costa, 2011). La competencia entre medios aumenta el ecosistema comunicativo, sus efectos, influencia y poder de estructuras económicas que están presentes dentro del mapa estructural de la sociedad-red. La saturación de la comunicación mediada por procesos técnicos bloquea la capacidad sensorial de las personas, tal y como lo afirma Costa (2011), lo cual va en sintonía con el modelo de comunicación efecto invernadero en la medida en que el océano de contenido inunda la generación de conocimiento y aumenta el nivel de persuasión e influencia de los medios sobre las personas en las maneras de interpretar o exponer la realidad social. El esquema de la ecología de la comunicación actual se concentra en cómo las tecnologías modifican los elementos fisiológicos, perceptuales, psicológicos y antropológicos de los individuos, en la medida en que el uso de los artefactos técnicos afectan los sentidos, las formas de socialización y los cambios en las costumbres sociales y culturales (Costa, 2011). La comunicación es entendida como una disciplina más allá de lo instrumental centrado en la magia de los medios técnicos; es una disciplina centrada en el ser humano como sujeto primigenio de los procesos de intercambios de sentido que permiten la interacción social entre muchos, bien sea de forma directa, bien sea por mediación de la técnica.

Los media cohabitan con los self media como efecto de las mutaciones de audiencias hacia los prosumidores, modificando uno de los aspectos claves de la teoría clásica de la comunicación, como el feedback: la fusión emisor-receptor origina en una misma órbita al productor, manipulador, generador y transmisor de mensajes, aduciendo un aumento de la participación social de los individuos en un entorno democrático de acceso a la información; no obstante este esquema participativo no extirpa el instrumento de control social que los medios significan para las estructuras de poder económico. Hay una convivencia pacífica entre los modelos de do- 
minación que influyen desde el emisor hacia el receptor por la aún vigente exposición de los medios masivos de información en las audiencias dispersas, así como el modelo horizontal de participación entre el emisor-receptor/perceptor, en la medida en que los canales cibernéticos difuminan el poder central de quien transmite el mensaje dando paso a la relación entre audiencias y prosumidores en red, quienes generan nuevas interacciones.

Las tres miradas propuestas como modelos ecológicos de la comunicación son un punto inicial para la creación o hallazgos de más esquemas de comunicación que inspiren enfoques teóricos focalizados en la descripción mapeada de los fenómenos comunicacionales. Por ahora, estas tres vertientes analizadas desde sus autores específicos lo que interrelacionan son aspectos acerca del impacto del avance tecnológico de la comunicación y su efecto en el comportamiento de los seres humanos dentro del ecosistema social. La nueva ecología cultural producto del avance de los prosumidores como generadores y consumidores de contenidos; el silogismo sobre el efecto invernadero producto de la saturación de información y su efecto en la modificación de los comportamientos humanos; la metáfora del tren metropolitano de una sociedad cosmopolita que interpreta una vida social entrecruzada desde múltiples variables donde la comunicación, las redes y los flujos de información son parte integral del ecosistema, constituyen tres maneras de enfocar teóricamente la ecología de la comunicación en la medida en que posibiliten interpretaciones acerca de las tendencias contemporáneas de la comunicación.

\section{Referencias}

Martín Barbero, J. (2004). Ciudadanía, democracia y diálogos sociales en América Latina. Recuperado de http://www.sinic.gov.co/SINIC/ Publicaciones $/$ PublicacionesDetalle.aspx $? \mathrm{ID}=618 \& \mathrm{TIPO}=\mathrm{P} \& \mathrm{SE}$ $\mathrm{RID}=20 \&$ SECID $=62 \& \mathrm{AREID}=2$

Martín Barbero, J. (2001). Claves de debate: televisión pública, televisión cultural: entre la renovación y la invención. En O. Rincón (comp.), Televisón pública: del consumidor al ciudadano (pp. 35-69). Bogotá: Convenio Andrés Bello. 
Martín Barbero, J. y Silva, A. (1997). Proyectar la comunicación. Bogotá: Tercer Mundo.

Cabello, R. y Levis, D. (eds.) (2007). Medios informáticos en la educacción a principios del siglo XXI. Buenos Aires: Prometeo.

Costa, J. (2011). Ecología de la comunicación e interacción social. Pensar la Publicidad. Revista Internacional de Investigaciones Publicitarias, 4(2), 17-24.

Dawson, R. (2006). Trend map for 2007 and beyond. Recuperado de http://rossdawsonblog.com/weblog/archives/2006/12/trend map_for_2.html

Dawson, R. (2008). Launch of the future of media lifecycle framework. Recuperado de http://rossdawsonblog.com/weblog/archives/2008/07/launch_of_the_f.html

Eco, U. (1993). Apocalípticos e integrados. Buenos Aires: Lumen.

Gonzálvez, V. (2014). Ciudadanía mediática: una mirada educativa. Madrid: Editorial Dykinson.

Horkheimer, M. y Adorno, T. W. (2008). Resumen sobre la industria cultural. En Crítica cultural y sociedad. Madrid: Akal.

Islas , O. (2009). La convergencia cultural a través de la ecología de medios. Comunicar: Revista Científica Iberoamericana de Comunicación y Educación, 33, 25-33.

Islas, O. (2015). La sociedad de la ubicuidad, los prosumidores y un modelo de comunicación para comprender la complejida de las comunicaciones digitales. Razón y Palabra, 65. Recuperado de http:// www.razonypalabra.org.mx/N/n65/varia/oislas.html 
Mattoni, A. (2012). Media practices and protest politics: How precarious workers mobilise. Farnham, UK: Ashgate.

Nardi, B. y O’ Day, V. (1999). Information ecologies: Using technology with heart. Boston, MA: MIT Press.

Postman, N. (1998). Five things we need to know about technological change. Recuperado de http://www.sdca.org/sermons mp3/2012/121229_postman_5Things.pdf

Postman, N. (1999). Building a bridge to the $18^{\text {th }}$ century: How the past can improve our future. Nueva York: Alfred A. Knopf.

Romano, V. (2004). Ecología de la comunicación. Hondarribia, Gipuzkoa: Hiru.

Romeu, V. y Piñón, M. (2014). La ecología comunicativa como germen de la comunicación estratégica: hacia un estado de la cuestión. $R a$ zón y Palabra, 18(86). Recuperado de http://ww35.razonypalabra.org.mx/N/N86/V86/14_RomeuPinon_V86.pdf

Sánchez, U., Botero, L. y Giraldo, A. (2011). Modelos de comunicación digital. Medellín Universidad de Medellín.

Scolari, C. (2015). Ecología de los medios. Barcelona: Gedisa.

Stephens, N. P. (2014). Toward a more substantive media ecology: Postman's metaphor versus posthuman futures. International Journal of Communication, 8, 19.

Vattimo, G. (2004). La sociedad transparente. Barcelona: Paidós. 